\title{
Светлана СорокА
}

DOI 10.14746/ssp.2017.2.1

Институт государственного управления

Черноморского национального университета имени Петра Могилы (Украина, г. Николаев)

\section{Новый Закон о бедных 1834 года как основа современной системы местного управления Великобритании}

\begin{abstract}
Аннотация статьи: Статья посвящена рассмотрению нового Закона о бедных 1834 года как основы для создания современной системы местного управления Великобритании. Проанализированы причины и предпосылки принятия Закона 1834 года, в частности определено, что началом реформ в местном управлении следует считать реформу избирательной системы в 1832 году. Определены основные нововведения Закона «Об изменениях к законодательству о бедных» и особенности их внедрения на практике. Рассмотрен процесс проведения реформы опеки над бедными 1834 года и утверждается, что это не были меры с целью отмены существующей системы, наоборот, они ее развили и усовершенствовали. Изменения, которые привнесла реформа вызревали давно. Свидетельством этого было принятие в конце XVIII - начале XIX века законодательных актов рекомендательного характера, которые содержали в себе отдельные мероприятия позже усовершенствованные и консолидированные в едином акте «Об изменениях к законодательству о бедных» 1834 года. Автор утверждает, что именно этот закон заложил фундамент современной системы местного самоуправления в Великобритании, а основанные согласно нему учреждения трансформировались в другие учреждения или с расширением сферы их влияния и функций, или с передачей некоторых функций другим институтам.
\end{abstract}

Ключевые слова: местное самоуправление, система местного управления Великобритании, Законы о бедных в Великобритании

B еликобритания прошла долгий путь эволюции местного управления, что позволило создать довольно успешную модель, которая является примером для многих стран. Особенностью становления местного самоуправления в Великобритании была последовательность реформ, учет местных традиций, постепенные и медленные изменения, которые исключали слом существующих механизмов и систем. Важным в этом контексте является факт, что часть зако- 
нов в отношении местного управления, принятых в XVII-XIX веках были разрешительными, то есть необязательными к исполнению. Это позволяло определить насколько популярными и необходимыми были предписания законодательства, выявить их положительные и отрицательные последствия, выработать дальнейшие действенные пути реформирования.

Основы современной системы местного управления Великобритании были заложены в XIX столетии в результате «муниципальной революции», которая проходила в три этапа, связанных с парламентскими реформами 1832 г., 1867 г. и 1884-1885 гг. Первую половину XIX в. можно считать периодом резкого роста социальных проблем, сохранения непрофессионального управления на местном уровне, а также периодом трансформации принципа «laissez - faire» - невмешательства государства в частные и местные интересы. В соответствии с новым Законом о бедных 1834 года местное управление Великобритании фактически оформилось как механизм социальной политики и сегодня является в первую очередь структурой которая обеспечивает социальную жизнь общины и ее территории. Основная гипотеза нашего исследования состоит в том, что именно новый Закон о бедных 1834 года заложил основы институциональной составляющей современной системы местного управления в Великобритании, о чем свидетельствует: во-первых то, что созданные в соответствии с законом организации были трансформированы в другие учреждения или с расширением сферы их влияния и функций, или с передачей некоторых функций другим институтам; во-вторых то, что принципы функционирования созданных структур были впоследствии перенесены на другие сферы местного управления.

\section{Предпосылки и причины принятия Нового Закона о бедных 1834 года}

Значительное влияние на изменения в сфере государственного управления Великобритании, в том числе и на местном уровне, оказала реформа избирательной системы 1832 года, которая получила название Акта о большой реформе (Great Reform Act) и стала значительным событием, ознаменовав переход от феодальной традиции равного представительства корпоративных единиц к новому демократическому принципу представительства от количества населения. 
В результате реформы количество избирателей возросло в полтора раза, хотя общем масштабе круг избирателей оставался достаточно ограниченным: лишь 1/6 мужского населения принимала участие в выборах. Согласно современным рассчетам до 1832 года к парламентских выборам были привлечены 509331 человек из 10207000 мужского населения (около 5\%), после 1832 г. количество избирателей увеличилось до 720184 человек (7,1\%) (Минеева, 2003, с. 77). Значительная часть предпринимателей, служащих, интеллигенции, а также рабочего класса были лишены парламентского представительства и влияния на политику. Однако, как утверждают исследователи, несмотря на ограниченность, реформа 1832 года оказала огромное влияние на внутриполитическое и конституционное развитие Великобритании, создала прецедент, благодаря которому британское общество убедилось, что политические институты и отношения, казавшиеся незыблемыми, могут быть успешно реформированы в соответствии с меняющимися социально-экономическими реалиями (Бунькова, 2014, с. 68).

Следующей сферой, которая требовала немедленного реформирования была сфера опеки над бедными. Как отмечал И. Редлих, проблемы в организации управления больше всего ощущались именно в этой сфере администрации, в которой в начале 30-х годов катастрофа фактически уже произошла (Редлих, 1907, с. 151). Проанализируем подробнее основные причины необходимости изменений в опеке над бедными.

1. Административная неэффективность системы. Почетные служители опеки над бедными, которые формально осуществляли свою деятельность на безвозмездной основе, уже не справлялись с возложенными на них обязанностями, что было обусловлено усложнением управления, большим количеством обязанностей, мобильностью населения.

2. Промышленная революция и развитие городов привели к стремительному увеличение количества населения и соответственно возрастанию количества бедных, требующих социальной опеки. Как свидетельствуют данные, население Великобритании удвоилось на протяжении 1760-1832 годов (Schweinitz, 1943, p. 114).

3. Отсутствие контроля со стороны населения. Система опеки над бедными, которая ранее основывалась на подлинном народном самоуправлении, в конце XVIII века перешла в полное распоряжение мировых судей и класса землевладельцев, из которого эти судьи 
избирались. Так князь А. И. Васильчиков охарактеризовал ситуацию накануне реформы 1834 года следующим образом: «Последние отпечатки самоуправления исчезли, затертые господством землевладельческого класса. Общины и приходы потеряли все свои права, собрания приходов были отменены, должностные лица и местные налоги непосредственно были оставлены на расправу мировых судей; аристократические кружки полностью завладели внутренним управлением страны, народ окончательно отошел от этого номинального самоуправления, которое целиком перешло в руки крупных и средних собственников, nobility и gentry» (Васильчиков, 1872, т. 1, с. 77). Если раньше общественная опека руководствовалась собранием всех прихожан (Vestry) и осуществлялась избранными ими церковными старостами (churchwarden), то позже вместо приходских собраний и выборных старост во главе ведомства находятся мировые судьи, назначаемые короной из владельцев с доходом $£ 100$, и надзиратели за бедными (overseers), которые определяются мировыми судьями из зажиточных землевладельцев (Васильчиков, 1872, т. 2, с. 6). Укрепление власти мировых судей происходило постепенно. Так, согласно Закона «О социальной помощи бедным» 1691 года, мировой судья в исключительных случаях получал право предлагать оказание помощи отдельным лицам, которые не имели имущества, хотя до этого такое право принадлежало исключительно органам прихода. На основании данного закона развилась практика, которая превратила исключение в правило и признавала за каждым мировым судьей право распоряжаться опекой над бедными по своему усмотрению.

4. Неэффективность контроля со стороны государственной власти. Правительственная власть не имела действенных механизмов влияния на местное управление. Некоторые функции государственного контроля местного управления имел Королевский тайный совет (Privy Council), который особыми приказами назначал и увольнял мировых судей, констеблей и других должностных лиц, утверждал постановления (bye-law) местных сборов и властей. Однако выполнение этих функций было лишь формальностью, о чем свидетельствует, в частности, то что ни разу не было использовано право Тайного совета на смещение с должности местного служащего или неутверждения местных постановлений. Право контроля над местным управлением имел Королевский суд (Court of King's Bench) и осуществлял его с помощью особых процедур: certiorari - изъятие дела верховным судом из производства суда низшей инстанции 
и mandamus - судебное предписание должностному или иному лицу совершить действия, которые оно обязано совершить по закону. Однако практика показывала, что самостоятельность местных властей настолько укоренилась, что даже Королевский суд действовал против них крайне осмотрительно, количество дел, которые выносились на его рассмотрение, уменьшалось каждый год.

5. Рост затрат на обеспечение социальной помощи бедным. Введение налога на бедных (poor rate) было предусмотрено Законом «О социальной помощи бедным» 1601 года. В нем отмечалось, что если приход не имеет средств для заботы о бедных, то должен быть установлен особый сбор в пользу малоимущих, который взимается со всех жителей пропорционально их прибыли. Налог на бедных стал своеобразной формой местного налога на прибыль, однако в случае аренды он уплачивался арендаторами имущества, а не его владельцами. Практика оказания социальной помощи бедным в денежной форме, не проводя разницы между трудоспособными и нетрудоспособными лицами, приводила к увеличению количества бедных и соответственно и налога на опеку над ними. Постепенно этот налог начал исчерпывать всю прибыль с земли. С 1750 по 1817 год налог на бедных вырос с 11 млн. к $£ 9,5$ млн. что составляло в среднем около 20\% доходности имущества в Великобритании (Васильчиков, 1872 , т. 2, с. 8). Во многих приходах земля не обрабатывалась из-за слишком высокого налога.

Если мы рассмотрим процесс проведения реформы опеки над бедными, которая основывалась на Законе 1834 года, то увидим, что это не были мероприятия с целью отмены существующей системы, наоборот, они ее развили и усовершенствовали. Изменения, которые привнесла реформа вызревали давно. Свидетельством этого было принятие в конце XVIII - начале XIX века. законодательных актов рекомендательного характера, которые содержали в себе отдельные мероприятия позже усовершенствованные и консолидированные в едином акте «Об изменениях законодательства о бедных». Мы охарактеризуем лишь некоторые из них. В 1782 году с целью более эффективной помощи и занятости бедных слоев населения был принят Закон «О социальной помощи бедным», так называемый Gilbert's Act. В соответствии с ним, по выявленному согласию 2/3 части Собрания прихода (Vestry), отдельные приходы могли создавать округа (Union of Parishes) и выбирать кандидатов, из которых мировые судьи утверждали опекунов бедных (guardian) и инспекторов работ- 
ных домов (visitor). В созданных союзах приходов должен был действовать общий работный дом, в котором проживали только старые и немощные бедняки. Для трудоспособных устанавливалась система помощи вне работных домов, которая обеспечивала их социальными выплатами и занятостью по месту жительства (Higginbotham, The History).

В 1818-1819 годах были приняты законы, получившие общее название Select Vestries Acts или Sturges-Bourne Acts. Первый закон «О регулировании Собраний жителей прихода» позволял приходам назначать специальный Комитет - Избранный совет прихода (Select Vestries) из выборных членов для тщательной проверки предоставления социальной помощи. Установлена была система голосования на Собрании прихода в зависимости от имущественного ценза. Землевладельцы, имевшие недвижимость стоимостью £50, имели право на один голос; за каждые последующие 225 лицо получало дополнительные голоса, но общим максимумом до шести голосов. Эта шкала была использована позже в Законе 1834 года для выборов Совета попечителей над бедными (Board of Guardians). Второй закон «О внесении поправок к Закону о социальной помощи бедным» был принят в 1819 году. Согласно акта, в связи с увеличением административной нагрузки по назначению социальной помощи на приходских смотрителей (неоплачиваемая должность) вводилась должность ассистентов смотрителя за бедными (assistant overseers) и сборщиков налогов (collector of rents) с денежным окладом. Стала более жесткой процедура требования предоставить социальную помощь по бедности, теперь вместо одного голоса мирового судьи нужно было два. Это должно было ограничить «великодушие» судей по назначению помощи любому, кто ее попросит.

Большинство законодательных актов, в том числе и описанные нами, имели разрешительный характер и не были обязательными к исполнению. Они предлагались к принятию приходам и округам на демократической основе - при согласии Собрания прихода или Съезда мировых судей. Например, так называемый Gilbert's Act был введен накануне 1834 года лишь в 200 общинах с населением 158864 человека (Васильчиков, 1872, т. 2, с. 10). За это время было создано около 100 союзов (Gilbert's Union), хотя истинное количество их было меньше, потому что заявленные союзы часто не начинали свою деятельность (Higginbotham, The History).

С целью изучения ситуации в сфере опеки над бедными и вы- 
работки мер для ее реформирования в течение 1832-1834 годов работала Королевская комиссия по правам бедных (Royal Commission into the Operation of the Poor Laws). Она проанализировала большое количество информации, в частности из предоставленных командой ассистентов отчетов непосредственно из приходов по всей стране и специальных опросов, которые были проведены в 1500 приходах (10\% от общего количества). Именно на основе отчета Королевской комиссии был разработан принятый Парламентом Закон с полным названием «Об усовершенствовании и лучшем применении Законов о бедных в Англии и Уэльсе» 1834 года.

\section{Основные положения Закона и особенности его внедрения}

Новый Закон о бедных 1834 года предусматривал следующее: 1) трудоспособный человек мог получить социальную помощь только в работном доме (workhouse), условия в котором были очень суровые, в частности, они были хуже, чем мог себе позволить самый низкооплачиваемый рабочий в стране, чтобы сделать это учреждение менее привлекательным для бедняков; социальная помощь вне работных домов предоставлялась только старым и немощным (Carter, 2009, p. 6); 2) создание Союзов по законодательству о бедных (Poor Law Unions), которые объединяли приходы, и построение работных домов в каждом из таких округов для оказания помощи бедным; 3) плательщики налогов в каждом Союзе приходов избирали Совет опеки над бедными (Board of Guardians) для сбора местного налога на бедных и предоставления социальной помощи; 4) правительством назначалась Центральная комиссия по правам бедных (Poor Law Commission) в составе трех человек для осуществления надзора за соблюдением закона по всей стране; 5) введение должностей с денежным окладом - инспекторов, делопроизводителей, кассиров и установление общих обязательных для всех управ правил делопроизводства и отчетности.

Определим основные результаты реализации Закона 1834 года и его значение для эволюции системы местного управления в Великобритании. Создание Союзов по законодательству о бедных (Poor Law Unions) на местах было доверено четырем Ассистентам членов Центральной Комиссии по правам бедных. Для этого они использовали уже существующую систему местных представительств - собирали советы местных землевладельцев, мировых судей, эсквайров 
и других важных лиц на местах. Ассистенты предлагали границы будущих Союзов и согласовывали их с существующими нормативными документами. Предполагалось, что Союзы будут примерно одинаковыми по площади, однако этому воспротивились большие землевладельцы, которые имели значительное влияние на местах. Поэтому округа были сформированы учитывая их интересы, а не интересы эффективного функционирования территорий.

Данные по количеству созданных Союзов несколько отличаются, однако дают возможность представить общую картину внедрения реформы. Согласно отчетам Центральной комиссии по правам бедных в 1836 году 7915 приходов были объединены в 365 Союзов, с общим участием населения в 6,2 млн. человек. Это составляло $43 \%$ населения Англии и Уэльса и соответствовало 65\% общей суммы местных налогов на бедность. До 1839 года были построены около 350 работных домов, преимущественно в сельских районах Южной Англии (Bloy, The Poor Law Commission, 2002). В течение трех лет после принятия нового Закона о бедных 13264 приходов Великобритании (90\%) были объединены в 568 Союзов по законодательству о бедных, возглавляемые Попечительскими советами (Board of Guardians) (Trattner, 1999, p. 53). По подсчетам князя А. И. Васильчикова в 1861 году уже насчитывалось 647 Союзов, которые объединяли 14600 приходов. В среднем на один округ приходилось 30000 жителей и 25 приходов (Васильчиков, 1872, т. 2, с. 12). Однако в 1854 году, после 20 лет внедрения реформы, 619 приходов с населением 2,2 млн. человек оставались на прежнем положении и не были объединены в округа. Центральная комиссия по правам бедных, хотя и имела право принудительно объединять приходы в округа, не спешила использовать его, а «терпеливо ожидала пока древние предрассудки умрут естественной смертью» (Васильчиков, 1872, т. 2, с. 28). Итак, процесс объединения приходов в Союзы по законодательству о бедных происходил недостаточно успешно, однако с учетом существующих на то время проблем в социально-экономической сфере и с учетом местных особенностей.

Подобной была и ситуация с оказанием социальной помощи бедным. Согласно Закону 1834 года трудоспособный человек мог получить ее только в работном доме. Однако по политическим и административным причинам оказалось невозможным неукоснительное соблюдение принципов, заложенных в Законе, особенно в северных и центральных промышленных районах. Еще в 1837 году Комиссары 
изменили свои инструкции, чтобы разрешить социальные выплаты в г. Ноттингеме, где создание нового Союза по законодательству о бедных совпало с периодом острой безработицы. Применение нового закона на севере Англии (в районах, которые не были исследованы при подготовке Закона), привело к катастрофическим последствиям. Кризис, вызванный падением биржевых индексов, привел к циклической безработице множества людей, которые не желали вступать в работные дома, несмотря на отсутствие других способов получения социальной помощи. Это заставило Центральную комиссию существенно скорректировать собственную политику. В 1842 году было издано распоряжение «О проверке работников получающих социальную помощь» (Outdoor Labour Test Order) для отдельных Союзов, которое предписывало правила для назначения социальных выплат трудоспособным лицам в обмен на выполнение различных видов ручной работы под наблюдением на территории работных домов. В таком случае половина социального пособия выдавалась в натуральной форме (едой, одеждой и т. п.) (Higginbotham, The 1842 Outdoor).

Вообще на практике местные Советы опеки над бедными пользовались большей свободой при назначении социальных выплат, чем предусматривалось законом. Распространенное мнение, что социальная помощь могла быть получена только в работном доме, было полностью ошибочным. Об этом ярко свидетельствуют статистические данные. В 1841 году из 1,3 млн. лиц, получавших социальную помощь, лишь 192000 находились в работных домах, остальные 1,1 млн. получали ее по месту жительства. Из общей суммы $£ 3884$ 000, использованных для выплат по бедности, лишь $£ 892000$ было потрачено в работных домах, в то время как £2 992000 были выплачены вне их. Данные за 1839-1840 годы демонстрируют подобные пропорции (Bloy, The Poor Law Amendment, 2002). Ситуация не изменилась и через 30 лет после принятия Закона, в 1863-1867 годах только 14\% бедных находились в работных домах, остальные получали социальные выплаты (Васильчиков, 1872, т. 2, с. 22).

Центральная комиссия периодически пыталась принимать меры для борьбы с предоставлением социальных выплат трудоспособным беднякам. В 1944 году было принято специальное распоряжение «О запрете предоставления социальной помощи» (Outdoor Relief Prohibitory Order) с целью наконец прекратить предоставление денежной помощи трудоспособным лицам, кроме отдельных должным образом мотивированных случаев. Если же такая помощь была 
назначена, Центральная комиссия должна была утвердить такое решение местной власти. Однако, как показала практика, цели этого распоряжения не были достигнуты, потому что значительное количество Союзов по делам бедных продолжали оказывать социальную помощь трудоспособным лицам вне работных домов (Higginbotham, The 1844 Outdoor). Не был эффективным и надзор Центральной комиссии над Советами опеки над бедными (Board of Guardians), потому что он ограничивался визитами инспекторов два раза в год и регулярным формальным предоставлением необходимых статистических данных (Bloy, The Poor Law Commission, 2002).

Именно трудности с реализацией положений Закона 1834 года, связанных с созданием округов по опеке над бедными и уменьшением социальных выплат, трактуются исследователями как неуспех реформы. Следует с этим не согласиться, потому что это скорее свидетельствует о эволюционном органическом характере внедрения закона, постепенной реализации его положений, учитывая местные особенности, без давления со стороны центральной власти. Собственно успешность реформы непосредственно была подтверждена финансовыми показателями, а именно уменьшением общей суммы налога на бедных уже в течение первого года ее реализации с £8 000000 до £5 750000 (Редлих, 1907, с. 162). И хотя в течение 1840 -х - 1860-х годов сумма налога колебалась в пределах £5-6 млн., однако общие расходы на опеку над бедными формировались уже не исключительно из налога на бедных, а также из других поступлений. Так в 1963 году фонд расходов формировался из налогов с приходов - £4,1 млн., налогов округов (Союзов) - £1,8 млн, субсидий правительства - £171,5 тыс. (Васильчиков, 1872, т. 2, с. 12).

\section{Создание институциональной основы современной системы местного управления}

Важнейшими достижениями Закона 1834 года, по нашему мнению, стали административные нововведения, которые заложили фундамент системы местного управления в Великобритании. Как отмечалось в Законе, во главе каждого округа по законодательству о бедных (Poor Law Union) назначался Совет из выборных членов - Board of Gardians. Каждый приход округа выбирал по одному члену Совета. Имущественный ценз члена управы (gardian) составлял $£ 40$ 
дохода. Мировые судьи округа тоже входили в Совет опеки над бедными по должности. Главными обязанностями Совета было определение должностных лиц для текущего управления, предоставление разрешения на строительство заведений для бедных, рассмотрение заявлений о предоставлении социальной помощи. Под ответственность Совета подпадали практически все действия для эффективного управления сферой опеки, он даже мог заключать договоры о займах для строительства работных домов. Его широкая самостоятельность в выборе средств управления могла быть ограничена лишь Собранием общины, перед которым он отчитывался, и, конечно, судами. Относительно количества членов Советов, то по всей стране было примерно 17000 опекунов над бедными (gardian) и 10000 мировых судей, следовательно в среднем 42 человека входили в одну управу (Васильчиков, 1872, т. 2, с. 12-13). Заседания должны были проходить не менее чем раз в неделю. Следует иметь в виду, что Board of Gardians не требовала постоянного присутствия всех членов, они собирались лишь в определенные дни. Для законности принятия решения требовалось присутствие только 3 членов. Поэтому такие Советы скорее можно назвать съездами или совещательными собраниями. Настоящее делопроизводство и управление обеспечивали должностные лица на штатном денежном окладе: ассистенты попечителей - assistant overseers, сборщики налогов - collectors, секретари - clerks, кассиры - treasurers. Непосредственно опекуны (gardian) не получали жалованья, но никакой действительной службы и не несли, потому что фактически на каждого из них приходилось 3-4 дня присутствия в году. Если же говорить о служащих, то их количество и денежное обеспечение в последующие годы стремительно росло. В 1844 году служащих по ведомству опеки над бедными было 8290 человек, в 1855 - 12835 , в 1861 - 15 000. Общая сумма оплаты их труда увеличилась за эти годы с £549 690 до £660 370 (Васильчиков, 1872, т. 2, с. 15). Учитывая вышесказанное, реформа 1834 года нанесла сокрушительный удар по принципу безвозмездной службы и господству высших слоев в местных учреждениях.

Для осуществления общего управления и контроля за системой опеки над бедными правительством назначалась Центральная комиссия по правам бедных (Poor Law Commission), которая имела следующие полномочия:

1) издание распоряжений и инструкций (general rule) обязательных к исполнению всеми служащими. В случае нарушений на 
служащих накладывались административные взыскания, которые могли быть обжалованы в судах и Собранием общины;

2) создание действенных местных административных единиц - Coветов опеки над бедными (Board of Gardians);

3) надзори контроль над местными управами спомощью инспекторов (ассистентов), которые предоставляли отчеты дважды в год;

4) назначение и увольнение с должностей служащих Советов опеки над бедными (Board of Gardians);

5) установление правил социального обеспечения бедных слоев населения.

По мнению исследователей, члены Центральной комиссии по правам бедных имели довольно широкие полномочия, такие, что фактически вся сфера опеки над бедными находилась под их абсолютным контролем (Maltbie, 1898, p. 234). Обязанностями Ассистентов членов Центральной комиссии были: инспекция районов и предоставления отчетов о преодолении бедности в разных приходах, расчет местных налогов в пользу бедных и установление вклада каждого прихода в Союз по законодательству о бедных, организация выборов Совета опеки над бедными (Board of Guardians) и управляющих работными домами.

Таким образом, впервые в Великобритании получило законодательное закрепление вмешательство правительства в дела местного самоуправления, однако это вмешательство было существенно ограничено ответственностью перед парламентом и подсудностью общим судебным предписаниям. Если первое реализовывалось путем подотчетности Президента Центральной комиссии перед Палатой Общин, членом которой он был. То относительно подсудности были установлены четкие и подробные правила: дела об ошибках в расчете или незаконном взимании налогов на бедных рассматривались мировыми судьями; жалобы общин о нецелесообразном использовании средств - мировыми съездами, они же оспаривали выборы членов управ и споры между округами; право обжалования распоряжений и инструкций Центральной комиссии предоставлялось любому заинтересованному лицу в Королевском суде.

О важности принятых в Законе «Об изменениях к законодательству о бедных» 1834 года административных нововведений свидетельствует тот факт, что все они позже были распространены на другие сферы местного управления в области образования, здравоохранения и т. д. В связи с этим целесообразно процитировать князя А. И. Васильчикова: «Ведомство опеки над бедными, разростаясь 
постепенно, принимает такие всеобъемлющие размеры, что становится основой местного самоуправления, поглощая всю деятельность общин и все их наличные силы и средства: из налога в пользу бедных образуется вся система земских смет и раскладок, из порядка обложения этого сбора (poor taxe) - весь порядок обложения всех прочих податей и повинностей, из правил управления и учреждения общественного призрения - весь многосложный механизм внутреннего самоуправления, так что во всех ведомствах и учреждениях, во всех самых разнообразных законодательных актах мы встречаем постоянные ссылки на этот первообраз английского selfgovernment, на законы о бедных - poor laws» (Васильчиков, 1872, т. 2, с. 3).

Другим свидетельством важности введенных Законом 1834 года учреждений является то, что на их основе был заложен институциональный фундамент местного управления Великобритании. Это можно проследить обратившись к Таблице 1, из которой следует, что созданные организации были трансформированы в другие учреждения или с расширением сферы их влияния и функций, или с передачей некоторых функций другим институтам.

Таблица 1

Учреждения образованные Законом «Об изменениях к законодательству о бедных» 1834 года и их трансформация

\begin{tabular}{|c|c|c|c|}
\hline $\begin{array}{c}\text { Годы } \\
\text { создания }\end{array}$ & \begin{tabular}{|c|} 
Центральный орган надзора \\
за местным самоуправлением
\end{tabular} & $\begin{array}{c}\text { Годы } \\
\text { создания }\end{array}$ & $\begin{array}{c}\text { Институты местного } \\
\text { самоуправления }\end{array}$ \\
\hline 1834 & $\begin{array}{l}\text { Центральная комиссия } \\
\text { правам бедных (Poor } \\
\text { праw } \\
\text { Commission) }\end{array}$ & 1834 & $\begin{array}{l}\text { Совет опеки над бедными } \\
\text { (Boards of Gardians) }\end{array}$ \\
\hline 1847 & $\begin{array}{l}\text { Департамент по правам бедных } \\
\text { (Poor Law Board) }\end{array}$ & 1875 & $\begin{array}{l}\text { Сельские санитарные ад- } \\
\text { министрации (Rural Sani- } \\
\text { tary Authorities) }\end{array}$ \\
\hline 1871 & $\begin{array}{l}\text { Департамент местного управле- } \\
\text { ния (Local Government Board) }\end{array}$ & 1894 & $\begin{array}{l}\text { Сельские районные советы } \\
\text { (Rural District Councils) }\end{array}$ \\
\hline 1919 & $\begin{array}{l}\text { Министерство здоровья } \\
\text { (Ministry of Health) }\end{array}$ & 1929 & $\begin{array}{l}\text { Советы графств } \\
\text { (County Councils) }\end{array}$ \\
\hline
\end{tabular}

\section{Выводы}

Формирование системы местного управления в Великобритании имеет долгую историю. Этот процесс происходил постепенно методом проб и ошибок. Новшества вводились осторожно, в отдельных 
сферах и на отдельных территориях. Большинство старых законов в сфере местного управления предусматривали демократические механизмы внедрения и вводились в действие по согласию большинства членов общины. Однако этот процесс был бессистемным и неуправляемым, он исключал возможность создания единой системы местного самоуправления. В начале XIX века созрели основные предпосылки для самоуправленческих реформ и большое значение для их внедрения имел Закон «Об изменениях к законодательству о бедных» 1834 года.

Анализ внедрения Закона 1834 года дает основания утверждать, что не все его цели были реализованы. Так и не удалось уменьшить социальные выплаты трудоспособным бедным и перенести центр социальной помощи в работные дома, также медленно происходил процесс объединения приходов в округа. Но это скорее свидетельствует об успехе реформы, о ее органичном внедрении с учетом социально-экономических условий в стране, местных особенностей, без давления со стороны центральной власти. Важнейшими нововведениями в сфере местного управления стали укрупнение исторически сложившихся приходов в целях повышения их административной эффективности, привлечение к местному управлению общественности и ее выборных представителей, создание на местах специализированных органов, призванных осуществлять функции местного управления, образование специального правительственного учреждения для контроля за местной администрацией - Центральной Комиссии по правам бедных. В это же время получила свое оформление такая отличительная черта английского самоуправления как значительная свобода действий местных институтов для достижения эффективного управления и обеспечения интересов общины, с одной стороны, и судебный и центральный контроль, с другой. Важно, что система местного управления трансформируясь и развиваясь в условиях индустриализации и урбанизации, увеличения количества населения и его миграции, возрастания социальных проблем эволюционировала от принципа невмешательства государства во внутренние дела общины к вынужденной централизации.

\section{Библиография}

Bloy M. (2002), The Poor Law Amendment Act: 14 August 1834, Victorianweb.org, http://www.victorianweb.org/history/poorlaw/plaatext.html, 6.01.2017. 
Bloy M. (2002), The Poor Law Commission, Victorianweb.org, http://www.victorianweb.org/history/poorlaw/plcommiss.html, 6.01.2017.

Бунькова Ю. В., Тамазов М. С., Аттоева Л. 3. (2014), Парламентская реформа 1832 года в Великобритании: начало полномасштабной модернизачии государственного строя, „Культура. Духовность. Общество”, № 14.

Carter P. (2009), How Cruel was the Victorian Workhouse/Poor Law Union? „Living the Poorlife", Nationalarchives.gov.uk, http://www.nationalarchives.gov.uk/ documents/cat-day-10-victorian-workhouse.pdf, 20.12.2016.

Higginbotham P., The 1842 Outdoor Labour Test Order, Workhouses.org.uk, http:// www.workhouses.org.uk/gco/outdoorlabourtestintro.shtml, 20.12.2016.

Higginbotham P., The 1844 Outdoor Relief Prohibitory Order, Workhouses.org. uk, http://www.workhouses.org.uk/gco/outdoorreliefprohibitoryintro.shtml, 28.12.2016.

Higginbotham P., The History of Poor Law Unions, Workhouses.org.uk, http://www. workhouses.org.uk/unions/, 20.12.2016.

Maltbie M. (1898), The English Local Government Board, „Political Science Quarterly", vol. 13, no. 2, http://www.jstor.org/stable/2140168, 19.12.2016.

Минеева Т. Г., Романовская В. Б. (2003), Английский парламент в XIII-XX веках, „Актуальные проблемы правоведения”, № 3.

Редлих И. (1907), Английское местное управление. Изложение внутреннего управления Англии в его историческом развитии и современном состоянии, Типография Альтшулера, т. 1, Санкт-Петербург.

Schweinitz K. (1943), England's Road to Social Security: from the Statute of Laborers in 1349 to the Beveridge Report of 1942, University of Pennsylvania Press.

Trattner W. (1999), From Poor Law to Welfare State. A History of Social Welfare in America, The Free Press, New York.

Васильчиков А. И. (1872), О самоуправлении. Сравнительный обзор русских u иностранных земских и общественных учреждений, Типография В. В. Пратц, т. 1, Санкт-Петербург.

Васильчиков А. И. (1872), О самоуправлении. Сравнительный обзор русских и иностранных земских и общественных учреждений, Типография В. В. Пратц, т. 2, Санкт-Петербург.

\section{Nowa ustawa o ubogich 1834 roku jako podstawa nowoczesnego systemu samorządu lokalnego w Wielkiej Brytanii}

\section{Streszczenie}

Artykuł został poświęcony nowej ustawie o ubogich 1834 roku jako podstawie tworzenia nowoczesnego systemu samorządu lokalnego w Wielkiej Brytanii. Przeanalizowano przyczyny i przesłanki przyjęcia ustawy z 1834 roku, w szczególności 
ustalono, że reformy władz lokalnych rozpoczęto od reformy systemu wyborczego w 1832 roku. Zidentyfikowano główne nowe rozwiązania ustawy o ubogich i uwarunkowania ich implementacji w praktyce. Rozpatrzono również proces przeprowadzenia reformy opieki nad ubogimi. Stwierdzono, że podjęte działania nie miały na celu diametralnej zmiany istniejącego systemu, wręcz przeciwnie w określonych aspektach utrwalały zastany stan rzeczy. Zmiany, które wprowadziła reforma były efektem ewolucji systemu pomocy osobom w trudnej sytuacji materialnej. Świadectwem tego było przyjęcie w końcu XVIII i na początku XIX wieku aktów prawnych, które zawierały w sobie poszczególne działania później udoskonalone i skonsolidowane w jednym akcie w randze ustawy z 1834 roku. Wskazano, że to właśnie wspomniana ustawa stworzyła podstawę nowoczesnego systemu samorządu lokalnego w Wielkiej Brytanii, zaś utworzone w myśl jej instytucje zostały później przekształcone w inne instytucje poprzez rozszerzenie ich funkcji lub z przeniesieniem niektórych zadań do innych instytucji.

Słowa kluczowe: samorząd terytorialny, system samorządu lokalnego Wielkiej Brytanii, ustawa o ubogich w Wielkiej Brytanii

\section{The new Poor Law 1834 as the basis of the modern local government system in Great Britain}

\section{Summary}

The paper is devoted to considerations on the new Poor Law 1834 as the basis of the modern local government system in Great Britain. On the basis of the analysis of the reasons for the adoption of the Law it is determined, in particular, that the beginning of reforms in local governance should be sought in the 1832 electoral reform. The main innovations of the Poor Law Amendment Act 1834, and especially their implementation in practice, are identified. The process of the reform of guardianship over the poor in 1834 is considered, and it is claimed that these measures were not aimed at abolishing the existing system; on the contrary, they developed and perfected it. The changes brought about by the reform had ripened for a long time, as evidenced by the adoption in the late 18th and early 19th centuries of recommendatory legislative acts which contained individual measures later improved and consolidated in the single Poor Law Amendment Act 1834. The author claims that this law laid the foundation of the modern system of local government in Great Britain and the institutions based on it evolved into other institutions, either expanding the scope of their influence and functions, or transferring certain functions to other institutions.

Key words: local government, the local government system of Great Britain, the Poor Law in Great Britain. 